\title{
Social Capital and Depressive Ill-Health -An Evaluative Approach to the Implementation of the Chronic Care Model (CCM)
}

\author{
Anne Lise Holm ${ }^{1 *}$, Anne Lyberg1, Ingela Berggren ${ }^{1,2}$, Sture Åström ${ }^{1,2}$, Elisabeth Severinson ${ }^{1}$ \\ ${ }^{1}$ The Centre for Women's, Family and Child Health, Faculty of Health Sciences, Buskerud \& Vestfold University \\ College, Kongsberg, Norway \\ ${ }^{2}$ Department of Nursing, Health and Culture, University West, Trollhättan, Sweden \\ Email: ${ }^{*}$ anne.holm@hsh.no
}

Received 25 July 2014; revised 23 August 2014; accepted 5 September 2014

Copyright $(2014$ by authors and Scientific Research Publishing Inc.

This work is licensed under the Creative Commons Attribution International License (CC BY). http://creativecommons.org/licenses/by/4.0/

(c) (1) Open Access

\section{Abstract}

Background: Social capital has been described as a person's sense of belonging as a result of the number and type of relationships she/he has, in which trust and reciprocity are especially important. Aim: To illuminate older persons' experiences of social capital and depressive illhealth after implementation of the CCM. Methods: Data were collected from nine participants resident in two districts of Norway by means of individual in-depth interviews. A qualitative hermeneutic analysis was performed. Results: Two overall themes, desire for a guardian and a wish for independence despite being dependent, and two themes emerging from the analysis. The first theme-searching for protection was based on three sub-themes overwhelmed by the emotional pain of other people, a sense of exclusion and worries about the future, while the second themethe need for a relationship with trustworthy persons comprised two sub-themes, namely, emotional pain was not understood and powerlessness to change the situation. The result of this study highlights the need for greater understanding on the part of healthcare professionals of how older persons manage their social relationships. Healthcare professionals require more knowledge about how negative self-beliefs held by older persons suffering from emotional pain, which can lead to reduced ability to trust other people. Another consequence is that fear of being dependent on other people can result in unwillingness to admit the need for help. Conclusion: This study highlights the lack of social capital in older persons who suffer from depressive ill-health. The implementation of the CCM does not appear to improve the situation. Older persons need to be more aware of their social needs and productive interactions in order to protect themselves and obtain

\footnotetext{
${ }^{*}$ Corresponding author.
} 
support from their social network.

Keywords

Chronic Care Model, Experiences, Depressive Ill-Health, Older Persons, Social Capital

\section{Introduction}

Over 350 million people fail to acknowledge that they suffer from depressive ill-health and do not seek treatment [1]. A recent World Health Assembly called on the World Health Organization and its member states to take action in this area [1]. Mental ill-health, such as depression, is a multifaceted phenomenon that has its roots in the realities of human beings" lived experiences [2]. The label "depressed" or "depressive" implies social sanctions often associated with fear and lack of understanding on the part of society [2]. One definition of mental ill-health is "each person's experience of living in his or her internal and external world during a period of personal despair or when his or her autonomy is temporarily impaired" ([3], p. 23). Depression in older persons is described as a complex health problem and has increased markedly over the past decade, indicating that in the future, older persons will suffer from this condition [4]. By the year 2020, depression is predicted to be the second largest cause of injury and disease in the world for all ages and both sexes [5]. Late-life depression is common in primary care settings, affecting at least $5 \%$ to $10 \%$ of older persons [6], although it remains under-detected in older persons who live in their own home [7] [8].

\subsection{Literature Review}

Putnam [9] defined social capital as networks, norms and trust that facilitate cooperation for mutual benefit within social organizations or communities. Social capital is developed, used and given value by the interaction between individuals [9]. It can constitute a sense of belonging that results from the number and type of relationships a person has, in which trust and reciprocity are especially important, as they enhance the ability to act both individually and collectively in ways that improve well-being [9]. According to Torche and Valenzuela [10], reciprocity is experienced as diffuse, taken for granted and rarely generalizable. For this reason social capital has been used to explain health disparities and promotion [11].

Different forms of social relationship have been described as essential when suffering from depressive illhealth [12]. Forsman [13] demonstrated that limited social networks were associated with depression and psychological distress in later life. Previous studies have revealed the impact of cognitive aspects of social capital on mental health [14] and positive correlations have been found between interpersonal trust, sense of security and mental health in populations including older persons [15]. The study by [16] demonstrated that when older persons searched for the meaning of their experiences of depressive ill-health and family support, they hovered between feelings of dignity and indignity. Nasser and Overholser [17] considered that relationships with friends could be more effective for alleviating depressive ill-health than those with family members. Depression is often accompanied by considerable social isolation and withdrawal from activities that would be essential in providing emotional support and assistance [6]. Family relationships may not always be good for a depressed person's health. Recent research has identified several negative consequences of social capital [18]. According to Kay [19], the networks and trusting relationships developed among people who share certain values can serve to exclude others and prevent new or different people from becoming part of the network. Nyqvist et al. [15] revealed that family and friends at the micro level were a key factor in the generation of social capital and well-being in older people. Social capital can accumulate within any group and be used to advance the private interests of its members, sometimes the detriment of others in the community, particularly poor people [20].

\subsection{Problem Statement}

This study represents the third evaluative phase of a larger investigation aimed at implementing the CCM for older persons suffering from depressive ill health in the community [12] [21] [22]. The researchers who conducted the present study evaluated older persons' experiences of social capital and depressive ill health after im- 
plementation of the Chronic Care Model (CCM), which has been used in several studies as a conceptual model for quality improvement. The CCM was developed by Wagner et al. [23] and comprises six components: 1) community resources and policy; 2) the health system and the organization of healthcare; 3) self-management support; 4) delivery system design; 5) decision support; and 6) clinical information systems. The final stage of the CCM is called productive interactions (see Figure 1), which can be assumed to have the same meaning as social capital. In this evaluation study, the participants were asked about their experience of change in social capital, i.e., productive interactions during the previous 12 months. Productive interactions between the healthcare team and patients have been reported to facilitate assessment, self-management support, optimization of therapy and follow-up, all of which are associated with positive outcomes [23]. Interactions can be productive when patients are active, informed and participate in their own care, for which they require the information, skills and confidence to make the best use of their involvement with the healthcare team. Self-management support is an important component of the CCM, as depressed older persons must be active in order to benefit from social interactions that can help them to better manage everyday life. Ensuring productive interactions by means of evidence-based care and self-management support has proved to be difficult in practice [23].

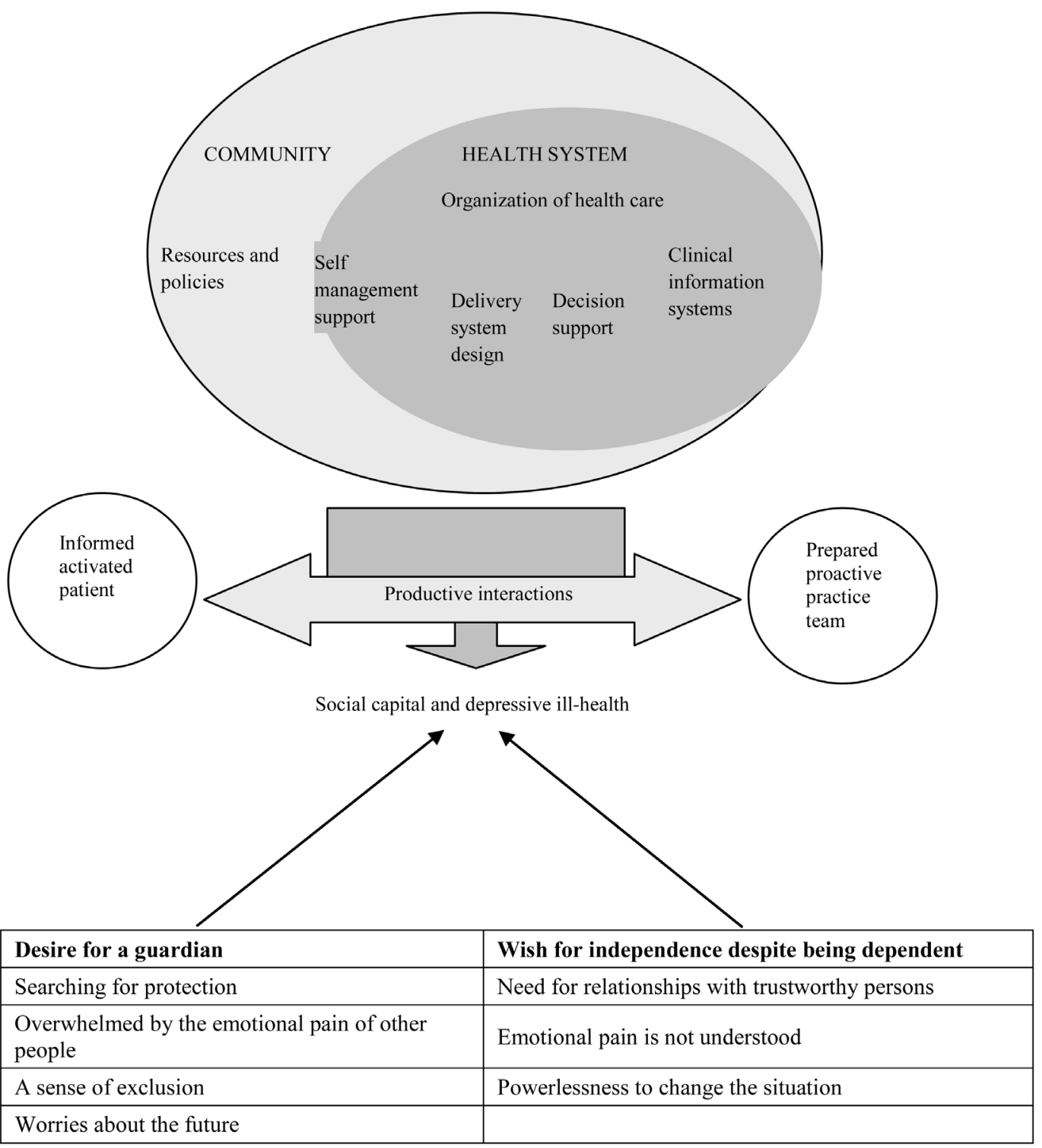

Figure 1. Social capital and depressive ill-health - an evaluative approach to the implementation of the Chronic Care Model (CCM). 


\subsection{Aim and Research Question}

This study is to illuminate older persons' experiences of social capital and depressive ill-health after implementation of the CCM. The research question is how did the participants describe their social capital when suffering from depressive ill-health?

\section{Methodology}

\subsection{Design}

This follow-up study employed a qualitative hermeneutic approach [24] [25] in order to interpret experiences of social capital and depressive ill-health. A key assumption in this approach is that meanings can only be understood and interpreted in the context in which they arise, i.e., through the lived experiences of those involved [24]. In healthcare, the overall goal of a qualitative hermeneutic approach is the provision of high quality care, which means continuing to explore what Gadamer [24] called "lived experiences" using intuition and empathy, thus creating hope and future opportunities [12]. In line with Gadamer's [24] philosophical hermeneutics, the methodological approach is both an underlying philosophy and a specific mode of interpretative reading of narrative texts. In this evaluation study the authors explored older persons' (60 years and more) experiences of social capital and depressive ill-health, which requires a certain pre-understanding of the topic [24].

The authors' pre-understanding is based on theoretical and practical knowledge gained from their professional experience as psychiatric nurses, supervisors and researchers. The pre-understanding of working as a psychiatric nurse was brought into the open, which allowed it to be reflected upon during the research process. The fourth author has a background in intensive care and is not familiar with the psychiatric care context. All authors have experience of conducting qualitative analyses.

\subsection{Trustworthiness}

When employing a Gadamerian approach the researcher must demonstrate the trustworthiness of the research process as well as the truthfulness of the analysis. Lincoln and Guba's [26] criteria are applicable to a Gadamerian research process. To facilitate the interpretation and analysis of data we included direct quotations to strengthen credibility and represent the participants' perspective. Consensus about the meaning of the statements is in line with the concept of confirmability. Neutrality or objectivity in hermeneutic qualitative research can be impossible to obtain. Transferability is often not applicable in a hermeneutic qualitative design, but we tried to ensure applicability to the reader's own context.

\subsection{Participants}

The participants comprised two men and seven women selected from a sample of 29 older persons from the two communities in Norway who had been interviewed one year earlier [12] [16] as part of the Chronic Disease Management-implementation and coordination of healthcare systems for depressed elderly people project (2011/2012). The inclusion criteria were: persons diagnosed with a depressive or mood disorder, able to understand and speak the Norwegian language, resident in a community in Norway, referred to community healthcare during the previous six months, over 60 years of age and willing to speak about their experiences. In this evaluation study, some of the participants in the first interview asked by the first and second authors proved to be good narrators and spoke about their social relationships if they would be willing to participate on a second occasion. The researchers (AL and ALH) made a list of those who expressed an interest, which they gave to the community mental health nurse, who phoned those on the list. The participants were interviewed in their own home. Their mean age was 67 years. The participants were interviewed either in their own homes or in the researchers' offices. Their mean age was 67 years. There were two men and seven female participants. Two suffered from bipolar disorder, while seven had been diagnosed with depression. Two were widows and seven were divorced. All of them lived alone.

\subsection{Data Collection}

Data were collected in 2013 by means of individual interviews that took the form of a dialogue between the first and second authors (ALH and AL) and the participants. The following question was posed, "Can you please tell 
me if you have any experiences of changes pertaining to social capital (productive interactions) and your depressive ill-health during the past 12 months?" The interviews, which were audio-taped and transcribed verbatim, lasted between 60 and 120 minutes.

\subsection{Data Analysis}

Interpretation of texts is a central part of the process of understanding in a Gadamerian hermeneutic approach. According to Lincoln and Guba [26], a key assumption in qualitative hermeneutic analysis is that meanings can only be understood in the context in which they occur. The first step in the analysis process was to increase understanding by reading the text several times and moving from the parts to the whole and back again in an iterative manner. The second step provided a deeper understanding of social capital and depressive ill health on a higher level of abstraction by searching for more general meaning patterns. Such interpretation is described as going beyond linguistics to find the essence of the text [24]. The authors discussed the interpretation several times to clarify and validate the meaning. They finally reached consensus and expanded the understanding of the experiences of social capital and depressive ill health reported by the older persons.

\subsection{Ethical Considerations}

The Ethical Guidelines for Nursing Research in the Nordic Countries, Northern Nurses Federation [27], were adhered to. Approval for the study was granted by The Regional Ethics Committee of Western Norway (No. 2010/2242). The interviews were conducted in a sensitive manner so as not to increase the older persons' feeling of being overwhelmed by their lived experiences of depressive ill-health [28]. The older persons were provided with detailed written information and signed a consent form. They were assured that their name and identity would not be disclosed and that they had the right to withdraw at any time. All data were stored in a locked and fireproof filing cabinet.

\section{Findings}

Two overall themes, desire for a guardian and a wish for independence despite being dependent, and two themes emerged from the analysis. The first theme-searching for protection was based on three sub-themes overwhelmed by the emotional pain of other people, a sense of exclusion and worries about the future, while the second - the need for a relationship with trustworthy persons comprised two sub-themes, namely, emotional pain is not understood and powerlessness to change the situation.

\subsection{Desire for a Guardian}

Social demands are part of a person's social capital and often related to productive interactions between individuals or organizations in a community. Although the participants had social capital it seemed fragmented and not very productive. The latter implies contact between various relationships, but in the present study, contact between family members, friends and professionals in the depressed older persons' social networks was by chance. Therefore, the older persons desired a guardian to help them with social participation and setting boundaries for themselves. Such a guardian can be a nurse or another mental health professional who can judge the right time to include the older person in social activities, while protecting her/him from social demands and expectations. Social activities and participation are considered a way to strengthen the experience of being capable.

"I force myself to listen to other people. But I have to think about myself too. So I'm working on this." (Woman No. 2)

\subsubsection{Searching for Protection}

The depressed older persons revealed their vulnerability, sensitivity and thus their need for protection in order to avoid being overwhelmed by the demands of social relationships. They stated that they felt obliged to listen to the problems of other vulnerable people. For this reason they needed to set boundaries for themselves and desired a guardian to protect them. They reported that when they refused contact and set boundaries they felt as if they had committed a crime. One woman stated,

"I cannot go to the Day Centre because I'm afraid of the other patients." (Woman No. 7) 
Another described her relationships with other people as follows:

"It's hell seeing the other patients struggle, I cannot stand it. I cannot say no to them." (Woman No. 9)

\subsubsection{Overwhelmed by the Emotional Pain of Other People}

Several of the participants described feeling guilty, having a serious moral conflict with themselves and being overwhelmed by other patients' emotional pain and suffering. They explained that they could not bear the other patients' burden. However, being unable to alleviate suffering increased their own guilt,

"One of the worst things when admitted was watching the suffering of the other patients. I knew many of them from the past. I cannot say no to them, so they hang on to me. I remember a young girl told me about her life, which really was a mess. She committed suicide that same night and I should have talked more and comforted her." (Woman No. 9)

One woman described having a guilty conscience when she refused to listen to other patients' problems, because it made her agitated. She explained that she could not support these patients,

"I find it difficult to set boundaries to protect myself. I experience a conflict within myself because I want to be a companion. I'm afraid that the patients may notice my agitation. I feel sorry for them and become upset on their behalf. But I cannot bear their burdens.” (Woman No. 2)

Some reported that they could not cope with the conflicts and subsequent guilt. One stated,

"I have told my family that I want to distance myself from all these conflicts and the subsequent guilt. I have to protect myself." (Woman No. 5)

\subsubsection{A Sense of Exclusion}

The participants revealed that they felt lonely and alone in the community, which led to a sense of exclusion. They stated that nobody cared about the elderly, especially persons who suffered from mental illness,

"My family does not live here and I experience that nobody cares. I don't belong here, I feel different, lonely and alone." (Woman No. 1)

Nor do they feel supported in their community. One woman stated,

"I don't feel included in the church. No one ever asks me about my depressive ill-health although they know about my problems." (Woman No. 4)

\subsubsection{Worries about the Future}

The participants described being deeply concerned about people they care about such as their family and friends. Some worried about the health of their children or grandchildren, others about how their grandchildren will manage in life, which also involved grief and loss. They described being concerned all the time and thinking catastrophic thoughts such as "What will happen next?" As a consequence their strength diminished. One participant stated that in her view this was "a wrong way to live",

"What worries me most is that my daughter has an eating disorder. I'm afraid she will suffer a breakdown one day." (Woman No. 1)

Another stated,

"My grandchild died in summer 2012. She was only six months old. Another grandchild has been in prison. I don't know what he did. I worry a lot about how it will end. There's a curse on my family." (Woman No. 5)

\subsection{A Wish for Independence despite Being Dependent}

The participants revealed that they wish to be independent despite their dependency on other people. Independence can be related to autonomy as well as social independence that can provide a view of dependency related to social demands and expectations. Freedom and autonomy are highly valued in our society. Is it possible to be 
independent and autonomous while admitting one's dependence? Anxiety can be related to the fear of becoming increasingly dependent on others and is understandable in the context of older persons' existential situation. It raises the question about how long one will be able to maintain one's autonomy and independence.

"Everybody tells me that I must be positive. Think about everything you can be positive about. I struggle to be positive, but I have too many mixed feelings inside." (Woman No. 5)

\subsubsection{The Need for a Relationship with Trustworthy Persons}

The participants explained that they need a nurse, a mental health professional or another person to help them see the realities of and opportunities in their daily life. One stated,

"When I experience that past struggles are coming back, my friend tells me, 'You must not think about past trauma any more, you must stop that'. He's right of course." (Woman No. 2)

The participants explained that they needed a human being who was not part of their social network in this role as they did not want to burden their family or friends. One of them stated,

"Even if you have a family you do not want to burden your relatives or friends. You have to find someone else to support you." (Woman No. 5)

Some of the participants revealed that they were abused and had lost trust in family and friends. One of them stated this,

"I was forced to guarantee a loan for my daughter when I was admitted to hospital in 2011. I was not aware of the consequences because I was confused after the operation. Today I'm a broken man; I feel abused and have lost all trust in my daughter. I have nothing to live for anymore." (Man No. 3)

\subsubsection{Emotional Pain Is Not Understood}

The participants revealed that they cannot expect too much of their family and that persons who have suffered themselves are more capable of understanding. They explained being unable to place too much strain on family and friends as they do not understand the emotional pain. One stated,

"One evening I became very worried about my son in Dubai and sent a text. My daughter in law phoned back and said, 'I will pray for you and so on'. They don't understand that it is of no comfort to me to hear this over and over again. I could have said, 'I know', but I cannot say that. They try their best, they really do." (Woman No. 5)

\subsubsection{Powerlessness to Change the Situation}

The participants had different experiences of powerlessness to change their situation in the community. One participant related about the instructions received when joining a support group,

"There were five members, mostly older persons (older than me). We were told not to talk about our mental ill health. But then we did not know what to do. So we quit the group." (Woman No. 7)

Another woman commented,

"Everybody tells me that I must be positive. Think about everything you can be positive about. I struggle to be positive, but I feel powerless with too many mixed feelings inside." (Woman No. 5)

\section{Discussion}

The aim of this study was to illuminate older persons' experiences of social capital and depressive ill-health after implementation of the CCM. The research question was: How did the participants describe their social capital when suffering from depressive ill-health?

Overall, the participants reported that their social capital was limited. The CCM does not seem to meet the social needs of older persons. The most important finding is the participants' desire for a guardian, which is associated with productive interactions that constitute social capital. A guardian can be related to the leadership function in the well-prepared team described by Holm and Severinsson [21]. However, social capital includes the de- 
pressed older person's entire network as described by Putnam [9], which requires a person they can trust for this role. Social support is part of the professional network in Norway and administered by the healthcare service. To get a decision about such social support is hard to obtain. The CCM does not seem to meet the social needs of depressed older persons. Wagner et al. [23] did not mention the need for a chronically ill person to have a network willing and able to cooperate with the mental healthcare team and its coordinator.

The depressed older persons were searching for protection by a guardian with expert knowledge, sensitivity and an understanding of their fear. However, such persons do not exist at present. In reality, the only person who can fulfill this role is a case/care manager or mental healthcare team coordinator defined in the CCM as a professional nurse, primary care physician or social worker. Nevertheless, the mental healthcare team coordinator cannot take on the role of guardian. Therefore, the question is who can ensure that older persons feel safe in their social interactions. In addition, there is a need to promote self-management for older persons who suffer from depressive ill-health. Holm et al. [12] reported one theme: relationships and togetherness. The support provided by social relationships did not imply a solution to the problems experienced by depressed older persons, but rather a person to person relationship that endowed life with meaning. Respect implied reciprocity as well as mutual acknowledgement of differences and was derived from the reality that one is fundamentally related to the other. This is supported by Hedelin and Jonsson [29] as well as other research demonstrating that social support can serve as a buffer against depression and facilitate recovery, as it prevents isolation [6] [30]. Peer support groups have been described as a way of obtaining mutual respect [31] [32].

Overwhelmed by the emotional pain of other people revealed that the older persons appeared distressed by seeing the needs and problems of fellow patients and being unable to help them. In such situations human beings seem to sense that they are responsible for others as outlined by Levinas [33]. However, when a person is extremely vulnerable, it is impossible to assume others' burden, which increased her/his own emotional pain. They wanted to be a good companion, free from guilt and inadequacy. The conscience can facilitate understanding of the other's emotional pain although it differs from one's own. The realization of one's existential aloneness becomes visible in this state of emotional pain and suffering, alienating the older person from her/himself. There appears to be an invisible partition between the world and the person. However, as the study by Holm et al. [12] revealed, by exhibiting a great deal of courage the participants experience being a person and not only a victim. Emotional pain seemed to increase in situations characterized by a sense of exclusion [34]. The wish for protection highlights the relational struggle and appeared to be a cry for connectedness with others while at the same time remaining autonomous. The older persons seemed to feel ignored, which has been defined as a process whereby certain individuals and groups are unjustifiably excluded and discriminated against [35]. The exclusion of older persons has been described as leading to the development of prejudices, ageism, popular stereotypes and taboos, damaging self-beliefs, lack of public discussion as well as alarmist popular and professional statements about burden and costs [36]. Discrimination in the provision of services for physical health problems in those who suffer from mental health conditions has also been reported [36]. Even when municipal resources are available to support older persons with depressive ill health, such individuals do not always seek care [36]. The result is isolation, refusal to make use of resources and silent suffering [22] [35] [36]. Exclusion and negative attitudes towards people with a range of mental disorders including depression have been investigated in studies undertaken in several countries [37]. Generally, beliefs about people with these disorders, societal attitudes and the desire for social distancing have been explored [38] [39]. Lasalvia [40] contributed to the understanding of depression-related discrimination by assessing the nature and severity of exclusion and discrimination reported by over 1000 persons with depression in 35 countries. Worries about the future is related to depression and anxiety. Older persons who suffer from depression seem to have fewer mental and social resources to distract them from thoughts of future disasters. Research has revealed that they increasingly worry about many things and that the type and degree of worry vary across the life span [41]. More intense worries were related to greater severity of depression among the oldest old. Emotional support from adult children had a positive effect on depression and worries, while social support was important for understanding catastrophic feelings about the future [42]. Depressed elderly persons seem unwilling to acknowledge finding it difficult to deal with stressful events but are less likely to be ambiguous about their future. Human beings have a desire to make sense of their life - as opposed to merely solving problems. Such a desire can change the focus from ill health and illness to the human being, giving a person time and space to talk about her/his worries related to grief and sadness that were not previously articulated. Personal growth can continue into old age [43]. However, one may become more sensitive about being taken seriously, which can easily lead to potential and optimism being undermined. Thus, the 
existential dimension of being in the world is not necessarily related to complete freedom from worry. In most situations dominated by anxiety, it is possible to increase an older person's strength by enhancing her/his dignity.

A wish for independence despite being dependent can be seen as every human being's need of freedom and autonomy. However, according to Levinas [33], nobody is completely free as each individual is always connected to other human beings. As an ethical principle, autonomy includes liberty, which implies independence from controlling influences and the capacity for intentional action [44], but at the same time one needs to reflect on the meaning of taking responsibility for the other [45]. The wish for independence means that the older persons recognize an opportunity to be connected that indicates a maturity that they are striving to achieve. Taking responsibility for other people seems to reduce the sense of being dependent [33]. However, the older persons might not be prepared for such responsibility and perhaps wish to avoid it. Many years ago Tillich [46] suggested that human beings must use their willpower to gain independency and self-confidence. In order to achieve this Tillich [46] suggested that one had to use one's self-affirmation of one's will. The study by Hillcoat-Nallétamby [47] revealed that dependence could have different meanings for older people, but certain meanings were common to all contexts: accepting help at hand; doing things alone; having resources such as family, friends, and money; and preserving physical and mental capacities. The need for a relationship with trustworthy persons can be interpreted as a search for new contextual and existential meaning [48]. This represents a challenge as older persons who suffer from depressive ill-health wish to be independent. Loneliness appears to be due to lack of trust and ability to relate to other people. However, social capital is not always productive, as it can be demanding and lacking in trust. The ability to establish a trusting relationship can depend on one's level of self- respect and self-confidence as well as respect for others. The burden of moral conflict seemed ever present for these older persons and increased their inner lack of well-being. Depressive ill-health can lead to inability to concentrate, accompanied by a wish to withdraw from social encounters while at the same time needing to trust another person. Thus productive interactions should be viewed in the light of the older persons' experiences. Lack of a person they can trust could hinder their potential and have a negative impact on how they look at the future. Tillich [46] suggested that lack of awareness of non-being resulted in an absence of self-affirmation and lack of trust. The older persons considered that they needed a person outside the family who understanded their emotional pain to help them find their own path into the future. In most desperate situations it is possible to increase a human being's strength by enhancing her/his self-determination and dignity. Research has revealed that in order to achieve self-management, the focus must shift to encouragement, engagement and support [22] [23]. Older persons need to see the various steps in the life cycle that help them towards self-overcoming [49] (Erikson, 1980). In order to reach such a state one can, as Stickley and Freshwater [50] suggested, reflect together with the patient on her/his vulnerability and longing to be confirmed, trusted and listened to. Such an approach can be a tool for improving nurses' and healthcare providers' awareness of their own role in the dialogue, especially if the depressed older person has a sense of powerlessness to change the situation. This can be related to feeling rejected in the social context of productive interactions, described as an arousal of emotional pain in recent research [51].

\section{Study Limitations}

This study has several limitations. Firstly, our sample is small and contains more women than men. It is possible that a larger sample and higher proportion of men would have produced different results. Hassan [52] stated that any research including reported data about past experiences was always weakened by the limitations of the individuals' memory and the influence of the human recall process. Such "recall bias" is not applicable in the present study, which only covers a 12 month period, as it is more pronounced when participants discuss events that occurred many years ago.

\section{Recommendations}

This study reveals that older persons need to enhance their social capital. Older persons suffering from depressive ill-health constitute a vulnerable group and require protection in order to be socially active. More research is needed about how older persons cope with experiences of exclusion in their social relationships [53]. In order to address their need for protection it will be necessary to develop a social inclusion action plan, especially in settings where other patients may add to their emotional pain. This study highlights the fact that experiences of 
being excluded from the social network increases emotional pain, which accords with research that has revealed a nullifying or impairing of equal enjoyment of rights [1] [5]. The experience of feeling violated and guilty increases when one is older and labeled as depressed [2]. Depressive ill-health has been described as a label that evokes fear and lack of understanding in society [2], which should be taken into consideration when organizing care. Healthcare professionals need to develop productive interactions that can empower older persons to obtain social contacts that can be helpful in their support network. These older persons wish to be independent, active and included in society [21] [22], but because of their depressive ill-health it must be understood that they may require more time to find people they can trust. Occasionally they even need persons to help them to set boundaries for themselves in situations where they are unable to do so. Such social contacts must be supervised by experienced health care professionals.

\section{Conclusions}

This study highlights the lack of social capital in older persons who suffer from depressive ill-health. The implementation of the CCM does not appear to improve the situation. Older persons need to be more aware of their social needs and productive interactions/and social capital in order to protect themselves and obtain support from their social network.

Social capital should be seen as an important aspect of future research on how to empower older people to maintain their roles and involvement in society as well as participate in their own healthcare. However, healthcare professionals require more education about how negative self-beliefs can reduce older persons' ability to understand the reciprocity and trust that are a part of their social capital.

\section{Acknowledgements}

We would like to express our deep thanks to the team members who participated. We also want to thank Gullvi Nilsson and Monique Federsel for reviewing the English language.

\section{Sources of Funding}

The study has been supported by grants from the Research Council of Norway, "Chronic Disease Management-implementation and coordination of healthcare systems for depressed elderly persons" (NFR, No. 204238/V50).

\section{References}

[1] World Health Organization (2012) Depression Is a Common Illness and People Suffering from Depression Need Support and Treatment. http://www.who.int/mediacentre/news/notes/2012/mental_health_day_20121009/en/

[2] Feely, M. and Long, A. (2009) Depression: A Psychiatric Nursing Theory of Connectivity. Journal of Psychiatric and Mental Health Nursing, 16, 725-737. http://dx.doi.org/10.1111/j.1365-2850.2009.01452.x

[3] Feely, M., Sines, D. and Long, A. (2007) Naming of Depression: Nursing, Social and Personal Descriptors. Journal of Psychiatric and Mental Health Nursing, 14, 21-32. http://dx.doi.org/10.1111/j.1365-2850.2007.01035.x

[4] Chapman, D.P. and Perry, G.S. (2008) Depression as a Major Component of Public Health for Older Adults. Preventing Chronic Disease, 5, 1-9. http://www.cdc.gov/pcd/issues/2008/jan/07_0150.htm

[5] World Health Organization (WHO) (2004) Global Burden of Disease. http://www.who.int/healthinfo/global burden disease/GBD report 2004update full.pdf

[6] Blazer, D.G. (2003) Depression in Late Life: Review and Commentary. The Journal of Gerontology: Series A, 58, 249265.

[7] Brown, E.L., Kaiser R.M.O. and Gellis, Z.D. (2007) Screening and Assessment of Late Life Depression in Home Healthcare: Issues and challenges. Annals of Long Term Care, 15, 27-32.

[8] Gellis, Z.D. (2010) Depression Screening in Medically Ill Homecare Elderly. Best Practices in Mental Health, 6, 1-16.

[9] Putnam R.D. (2000) Bowling Alone: The Collapse and Revival of American Community. Simon \& Schuster, New York.

[10] Torche, F. and Valenzuela, E. (2011) Trust and Reciprocity: A Theoretical Distinction of the Sources of Social Capital. European Journal of Social Theory, 14, 181-198. http://dx.doi.org/10.1177/1368431011403461 
[11] Lindström, M. (2008) Social Capital and Health-Related Behaviour. In: Kawachi, I., Subramanian, S.V. and Kim, D., Eds., Social Capital and Health, Springer, New York, 215-238. http://dx.doi.org/10.1007/978-0-387-71311-3 10

[12] Holm, A.L., Lyberg, A., Lassenius, E., Berggren, I. and Severinsson, E. (2013) Older Persons' Lived Experiences of Depression and Self-Management. Issues in Mental Health Nursing, 34, 757-764. http://dx.doi.org/10.3109/01612840.2013.809829

[13] Forsman, A. (2012) The Importance of Social Capital in Later Life. Mental Health Promotion and Mental Disorder Prevention among Older Adults. Dissertation, Nordic School of Public Health NHV, Gothenburg.

[14] De Silva, M., McKenzie, K., Haprpham, T. and Huttly, S.R.A. (2005) Social Capital and Mental Illness: A Systematic Review. Journal of Epidemiology and Community Health, 59, 619-627. http://dx.doi.org/10.1136/jech.2004.029678

[15] Nyqvist, F., Finnäs, F., Jakobsson, G. and Koskinen, S. (2008) The Effect of Social Capital on Health: The Case of Two Language Groups in Finland. Health Place, 14, 347-360. http://dx.doi.org/10.1016/j.healthplace.2007.09.001

[16] Lyberg, A., Holm, A.L., Lassenius, E., Berggren, I. and Severinsson, E. (2013) Older Persons' Experiences of Depressive Ill-Health and Family Support. Nursing Research and Practice, 2013, Article ID: 837529. http://dx.doi.org/10.1155/2013/837529

[17] Nasser, E.H. and Overholser, J.C. (2005) Recovery from Major Depression: The Role of Support from Family, Friends and Spiritual Beliefs. Acta Psychiatrica Scandinavia, 11, 125-132. http://dx.doi.org/10.1111/j.1600-0447.2004.00423.x

[18] Bowen, G.A. (2009) Social Capital, Social Funds and Poor Communities: An Exploratory Analysis. Social Policy and Administration, 43, 245-269. http://dx.doi.org/10.1111/j.1467-9515.2009.00660.x

[19] Kay, A. (2006) Social Capital, the Social Economy and Community Development. Community Development Journal, 41, 160-173. http://dx.doi.org/10.1093/cdj/bsi045

[20] Castle, E.N. (2002) Social Capital: An Interdisciplinary Concept. Rural Sociology, 67, 331-349. http://dx.doi.org/10.1111/j.1549-0831.2002.tb00107.x

[21] Holm, A.L. and Severinsson, E. (2013) Interdisciplinary Team Collaboration during Discharge of Depressed Older Persons-A Norwegian Qualitative Implementation Study. Nursing Research and Practice, 2013, Article ID: 794743. http://dx.doi.org/10.1155/2013/794743

[22] Holm, A.L. and Severinsson, E. (2013) Reflections on the Ethical Dilemmas Involved in Promoting Self-Management. Nursing Ethics, 21, 402-413. http://dx.doi.org/10.1177/0969733013500806

[23] Wagner, E.H., Glasgow, R.E., Davis, C., et al. (2001) Quality Improvement in Chronic Illness Care: A Collaborative Approach. Journal of Quality Improvement, 27, 63-79.

[24] Gadamer, H.G. (2004) Truth and Method. Interactive Sciences Ltd., Gloucester.

[25] Polit, D.F. and Beck, C.T. (2010) Essentials of Nursing Research: Appraising Evidence for Nursing Practice. Wolters Kluwer/Lippincott Williams \& Wilkins, Philadelphia.

[26] Lincoln, Y.S. and Guba, E.G. (1985) Naturalistic Inquiry. Sage Publications Inc., London.

[27] Northern Nurses' Federation (2003) Ethical Guidelines for Nursing Research in the Nordic Countries. http://www.sykepleien.no/ikbViewer/Content/337889/SSNs\%20etiske\%20retningslinjer.pdf

[28] Liamputtong, P. (2007) Researching the Vulnerable: A Guide to Sensitive Research Methods. Sage, London.

[29] Hedelin, B. and Jonsson, I. (2003) Mutuality as Background Music in Women's Lived Experience of Mental Health and Depression. Journal of Psychiatric and Mental Health Nursing, 10, 317-322. http://dx.doi.org/10.1111/1540-5885.310001-i1

[30] Ahlström, B.H., Skärsäter, I. and Danielsson, E. (2009) Living with Major Depression: Experiences from Families' Perspectives. Scandinavian Journal of Caring Sciences, 23, 309-316. http://dx.doi.org/10.1111/j.1471-6712.2008.00624.x

[31] Hogan, B.E. (2002) Social Support Interventions: Do They Work? Clinical Psychological Review, 22, 383-442. http://dx.doi.org/10.1016/S0272-7358(01)00102-7

[32] Eysenbach, G. (2004) Peer-Review and Publication of Research Protocols and Proposals: A Role for Open Access Journals. Journal of Medical Internet Research, 6, e37. http://dx.doi.org/10.2196/jmir.6.3.e37

[33] Levinas, E. (1994) Ethics and Infinity. Conversations with Philippe Nemo. Duquesne University Press, Pittsburgh.

[34] Holm, A.L. (2009) The Meaning of Emotional Pain. Analytic Interpretative Research on Women's Experiences of Mental Health Problems. Doctoral Thesis, University of Stavanger, Stavanger.

[35] World Health Organization and World Psychiatric Association (2002) Reducing Stigma and Discrimination against Older people with Mental Disorders. WHO, Geneva.

[36] De Mendonca Lima, C.A. (2004) The Reduction of Stigma and Discrimination against Older People with Mental Disorders: A Challenge for the Future. Archives of Gerontology and Geriatrics, 38, 109-120. 
http://dx.doi.org/10.1016/j.archger.2004.04.018

[37] Jorm, A.F. and Reavley, N. (2013) Depression and Stigma: From Attitudes to Discrimination. The Lancet, 381, 10-11. http://dx.doi.org/10.1016/S0140-6736(12)61457-3

[38] Griffiths, K.M., Christensen, H. and Jorm, A.F. (2008) Predictors of Depression Stigma. BMC Psychiatry, 8, 25-37. http://dx.doi.org/10.1186/1471-244X-8-25

[39] Jorm, A.F. and Oh, E. (2009) Desire for Social Distance from People with Mental Disorders. The Australian and New Zealand Journal of Psychiatry, 43, 183-200. http://dx.doi.org/10.1080/00048670802653349

[40] Lasalvia, A., Zoppei, S., Van Bortel, T., et al. (2012) Global Pattern of Experienced and Anticipated Discrimination Reported by People with Major Depressive Disorder: A Cross-Sectional Survey. The Lancet, 381, 55-62. http://dx.doi.org/10.1016/SO140-6736(12)61379-8

[41] Jeon, H.-S., Dunkle, R. and Roberts, B.L. (2006) Worries of the Oldest-Old. Health \& Social Work, 31, 256-265. http://dx.doi.org/10.1093/hsw/31.4.256

[42] Lee, I. and Dunkle, R.E. (2010) Worries, Psychosocial Resources and Depressive Symptoms among the South Korean Oldest Old. Aging and Mental Health, 14, 57-63. http://dx.doi.org/10.1080/13607860903420997

[43] Rizzo Parse, R. (2010) Human Dignity: A Human-Becoming Ethical Phenomenon. Nursing Science Quarterly, 23, 257-262. http://dx.doi.org/10.1177/0894318410371841

[44] Beauchamp, T. and Childress J. (2001) Principles of Biomedical Ethics. 5th Edition, Oxford University Press, Oxford.

[45] Erikson, K. (1997) Understanding the World of the Patient, the Suffering Human Being: The New Clinical Paradigm from Nursing to Caring. Advanced Practice Nursing Quarterly, 3, 8-13.

[46] Tillich, P. (1970) The Courage to Be. Collings Clear-Type Press, London.

[47] Hillcoat-Nalléamby, S. (2014) The Meaning of "Independence" for Older People in Different Residential Settings. Journals of Gerontology: Series B, 69, 419-430. http://dx.doi.org/10.1093/geronb/gbu008

[48] Erikson, K. (2006) The Suffering Human Being. Nordic Studies Press, Chicago.

[49] Erikson, E.H. (1980) Identity and the Life Cycle. W.W. Norton \& Company, London.

[50] Stickley, T. and Freshwater, D. (2006) The Art of Listening in the Therapeutic Relationship. Mental Health Practice, 9, 12-17. http://dx.doi.org/10.7748/mhp2006.02.9.5.12.c1899

[51] Eisenberger, N.I., Lieberman, M.D. and Williams, K.D. (2003) Does Rejection Hurt? An fMRI Study of Social Exclusion. Science, 302, 290-292. http://dx.doi.org/10.1126/science.1089134

[52] Hassan, E. (2005) Recall Bias Can Be a Threat to Retrospective and Prospective Research Designs. The Internet Journal of Epidemiology, 3, No. 2. http://ispub.com/IJE/3/2/13060

[53] Joachim, G. and Acorn, S. (2000) Stigma of Visible and Invisible Chronic Conditions. Journal of Advanced Nursing, 32, 243-248. http://dx.doi.org/10.1046/j.1365-2648.2000.01466.x 
Scientific Research Publishing (SCIRP) is one of the largest Open Access journal publishers. It is currently publishing more than 200 open access, online, peer-reviewed journals covering a wide range of academic disciplines. SCIRP serves the worldwide academic communities and contributes to the progress and application of science with its publication.

Other selected journals from SCIRP are listed as below. Submit your manuscript to us via either submit@scirp.org or Online Submission Portal.
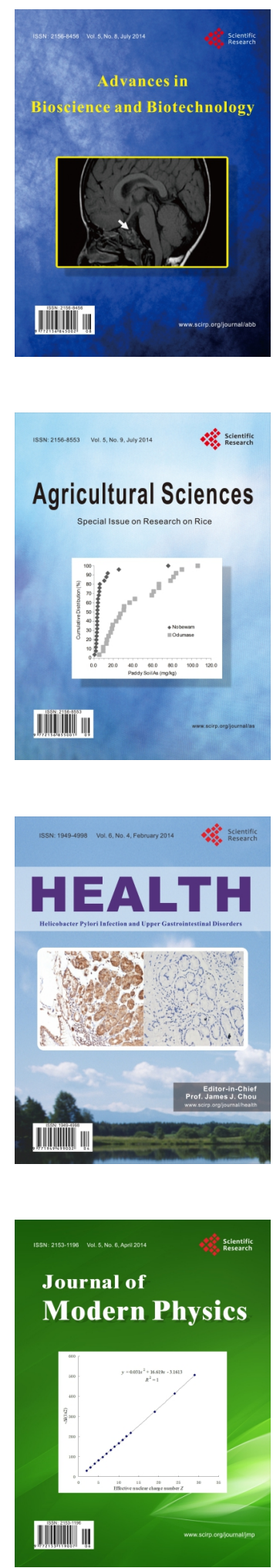
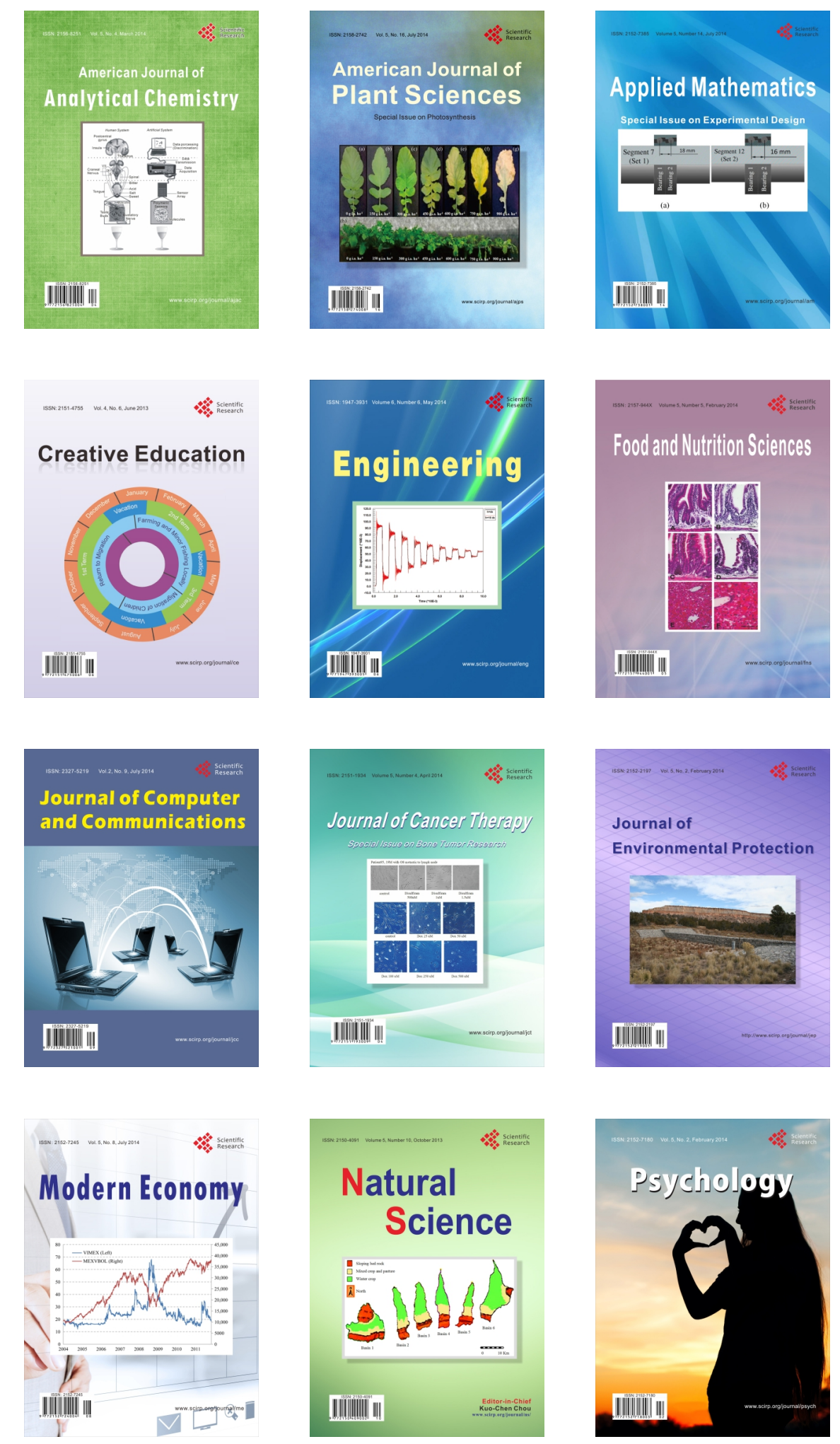